\title{
An in vivo electromyographic evaluation of pain relief using different therapies in masticatory myalgia patients
}

\author{
Parvathi K. Balakrishnan ${ }^{1}$, Sowmya M. Kumar ${ }^{1}$, Purushotham Chippala ${ }^{2}$, Chethan Hegde ${ }^{1}$ \\ ${ }^{1}$ Department of Prosthodontics, Nitte (Deemed to be University), AB Shetty Memorial Institute of Dental Sciences (ABSMIDS), \\ ${ }^{2}$ Nitte Institute of Physiotherapy (NIPT), Nitte (Deemed to be University), Mangalore, India
}

\begin{abstract}
J Korean Assoc Oral Maxillofac Surg 2020;46:321-327)
Objectives: This study is aimed to evaluate and compare the effect of moist heat fomentation therapy with ultrasound therapy in patients with the masticatory myalgia.

Materials and Methods: The study was conducted on 42 patients with masticatory myalgia, dividing them into two groups; Group A (21 patients), received moist heat therapy and Group B (21 patients), received ultrasound therapy for seven effective days. Prior and after the treatment the numeric rating scale (NRS) and the electromyography (EMG) scores were recorded and compared. The observations were analyzed clinically and statistical support was taken to assess the NRS and EMG data.

Results: Irrespective of the groups, patients testified a significant reduction in pain after the treatment. From the EMG readings; even though the standard deviation for each group was varied considerably, EMG recorded an improved muscle activity. Statistical analysis was used to assess and identify the best treatment methodology between the two modalities.

Conclusion: From the statistical analysis, it is concluded that, though both the therapies had significantly reduced the symptomatic response, it is moist heat fomentation that improved muscle activity both statistically and clinically in comparison to ultrasound.
\end{abstract}

Key words: Temporomandibular disorder, Therapeutic ultrasound, Surface electromyography, Moist, Heat

[paper submitted 2020. 1. 31 / revised 2020. 3. 27 / accepted 2020. 4. 1]

\section{Introduction}

The masticatory system is a sophisticated system composed of temporomandibular joint (TMJ), muscles, ligaments, and teeth. The TMJ is also known as the bi-arthrodial joint, compound joint, or ginglymoarthroidal joint because it allows for hinge movement and translatory movement ${ }^{1}$. Temporomandibular disorder (TMD) is a musculoskeletal ailment that affects almost $25 \%$ of the population. Common causes include behavioral stress, parafunctional habits, and direct or indirect trauma to the associated musculature. However, $70 \%$

\footnotetext{
Sowmya M. Kumar

Department of Prosthodontics, Nitte (Deemed to be University), AB Shetty Memorial Institute of Dental Sciences (ABSMIDS), Mangalore 575018, India

TEL: +91-9900323937 FAX: +91-0824-2204305

E-mail:drsowmyamk@yahoo.com

ORCID: https://orcid.org/0000-0003-0696-0697

(c) This is an open-access article distributed under the terms of the Creative Commons Attribution Non-Commercial License (http://creativecommons.org/ licenses/by-nc/4.0/), which permits unrestricted non-commercial use, distribution, and reproduction in any medium, provided the original work is properly cited.

Copyright (C) 2020 The Korean Association of Oral and Maxillofacial Surgeons. All rights reserved.
}

of the cases are due to malposition of the temporomandibular disc. Pain compromises the functional activity of masticatory muscle, resulting in uncoordinated and hyperactive activity ${ }^{2}$. Thus, any variation in the masticatory muscle activity pattern during static and dynamic function is an efficient means to detect disturbance in mandibular activity. Orofacial pain in the preauricular region, tenderness on palpation, reduced mouth opening due to muscle spasm, a clicking or popping sound, and deviation and deflection in the path of mandibular movements are common signs and symptoms of this ailment ${ }^{3}$.

Surface electromyography (SEMG) has been used as a diagnostic tool for TMD. It is used to detect various pathological and dysfunctional conditions like hyperactivity, hypoactivity, and muscle fatigue, along with valuation of the effectiveness and success of personalized treatments ${ }^{4}$.

Various treatment modalities are available for TMD, and physical therapies are the first line of treatment to improve and restore function of the masticatory apparatus. Almost $90 \%$ of patients responded positively to conservative therapies, which include behavioral modification or self-management, jaw exercises, and physical therapies ${ }^{5}$. Thermo-therapy 
is the oldest modality and is still well accepted and commonly used as a self-manageable home remedy. Application of moist heat on affected muscles is highly effective since diffusion of moist heat helps in vasodilation, thereby improving the blood flow to the affected muscles and removal of metabolic waste products to provide relief from joint dysfunction and muscle pain ${ }^{6}$.

Ultrasound (US) is used as both a diagnostic and a therapeutic measure in the field of medicine. Similarly, a low pulse ultrasound of about $1 \mathrm{MHz}$ has been widely used to treat tendinitis and bursitis since the early 1950s. Production of acoustic energy in the ultrasonic range causes heat production and vibration of tissues through a process called cavitation ${ }^{7}$. The main objectives of electrotherapy modalities, such as ultrasound, are pain relief and muscle hyperactivity or spasm relief $^{8}$. This approach is believed to be superior to superficial thermotherapy because it allows the heat to penetrate into deeper tissues, improving the extensibility of collagen tissues and relieving joint stiffness ${ }^{9}$.

Although a subjective analysis of the effectiveness of moist heat and ultrasound therapy has been documented, there is less evidence for objective analysis of the same approach. Therefore, this research was performed to evaluate and compare the efficacy of moist heat and ultrasound therapies on relieving the symptoms associated with TMD, using a numeric rating scale (NRS) as a subjective analysis tool and SEMG as an objective analysis tool to assess and understand the pre-interventional and post-interventional masseter and temporalis muscle tonicities in patients with masticatory muscle myalgia.

\section{Materials and Methods}

The study included 42 masticatory myalgia patients that reported to the Department of Prosthodontics, Nitte (Deemed to be University) from November 2017 to September 2019. The study was approved by the Ethical Committee of AB Shetty Memorial Institute of Dental Sciences (No. ABSM/ EC31/2017). Informed consent from patients between 2050 years of age was obtained, and the patients were then screened using Research Diagnostic Criteria for Temporomandibular Disorder (DC/TMD) for Axis- $1^{10}$.

Inclusion criteria:

-Subjects with masticatory muscle pain.

Exclusion criteria:

-Subjects suffering from any neurologic disorders.

-Subjects with a past history of rehabilitation therapy for
TMD.

-Subjects on analgesics.

-Subjects with traumatic injuries.

-Subjects with a previous history of rheumatic disorders, fractures, or surgeries.

-Subjects suffering from persistent pain for three or more months.

-Subjects with any pathologic findings on TMJ radiographs.

The procedure was performed with the help of a primary and a secondary investigator to prevent subject bias. Initial diagnostic evaluation was conducted by the primary investigator using the digital palpation method for evaluating the affected muscle ${ }^{1}$. The temporalis muscle was palpated at the anterior, middle, and posterior regions. The masseter muscle was palpated by instructing the patient to clench their teeth. The severity of pain was rated on the $\mathrm{NRS}^{11}$ (Fig. 1) from 0 to 10 , where a score of 0 was perceived as no pain and a score of 10 was perceived as the highest pain level. Tonicity

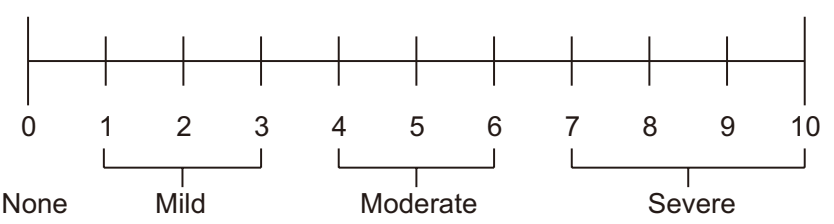

Fig. 1. Numeric rating scale used for pain assessment. Parvathi K. Balakrishnan et al: An in vivo electromyographic evaluation of pain relief using different therapies in masticatory myalgia patients. J Korean Assoc Oral Maxillofac Surg 2020

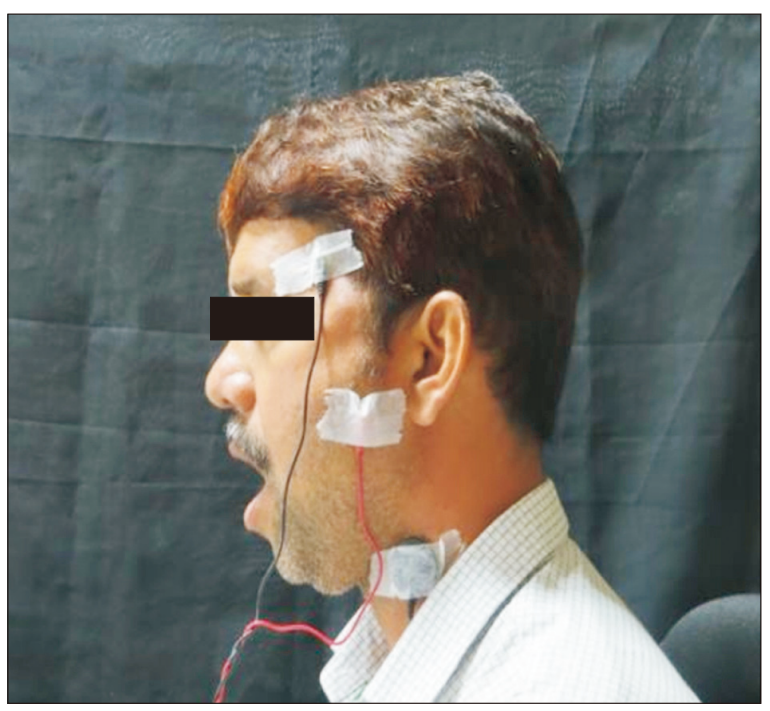

Fig. 2. Electromyography recording of temporalis muscle in function. Parvathi K. Balakrishnan et al: An in vivo electromyographic evaluation of pain relief using different therapies in masticatory myalgia patients. J Korean Assoc Oral Maxillofac Surg 2020 
of affected muscles was documented using electromyography (EMG).(Fig. 2) After thorough examination, patients were randomly divided into two groups of 21 subjects each for treatment.

Group A: Patients received moist heat therapy for $20 \mathrm{~min}-$ utes as a home remedy ${ }^{2,12}$. This therapy was repeated twice a day with a time interval of eight hours for seven consecutive days. The therapy was performed by placing a hot, wet towel over the affected region for 20 minutes.

Group B: Patients received ultrasound therapy at the Department of Physiotherapy ${ }^{13}$. The therapy was performed over the affected muscles using an ultrasound probe with a diam-

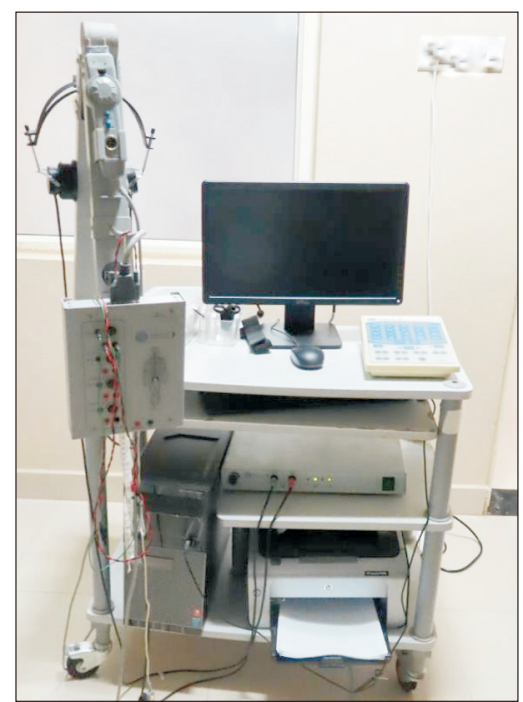

Fig. 3. RMS Salus 4C electromyograph machine (RMS, India). Parvathi K. Balakrishnan et al: An in vivo electromyographic evaluation of pain relief using different therapies in masticatory myalgia patients. J Korean Assoc Oral Maxillofac Surg 2020 eter of $5 \mathrm{~cm}^{2}$. Patients that underwent this treatment were exposed to a continuous mode of ultrasound energy at $0.8 \mathrm{~W}$ of power and $1 \mathrm{MHz}$ of frequency (used for deeper tissues) for 10 minutes in the area of interest. This session was repeated for seven working days.

The post treatment pain response was analyzed by the secondary investigator who was blinded to type of treatment. Pain severity was recorded using a NRS. Similarly, EMG readings were gathered to analyze the effectiveness of each modality post-intervention. The EMG records muscle activity by trapping and measuring the electricity generated by the muscles. These readings are collected using electrodes and transmitted to the electromyograph for presentation as an electromyogram.(Fig. 3)

\section{Results}

Data were analyzed statistically using the unpaired t-test between the two groups. Paired t-test was used to determine the effectiveness of each treatment modality for Group A (moist heat) and Group B (ultrasound). IBM SPSS Statistics (ver. 22; IBM, Armonk, NY, USA) was used to analyze the data, and $P<0.001$ was considered statistically significant. Previous experiments noted that patients with TMD had lower EMG readings for the affected muscles than did normal individuals $^{5,14-16}$.

\section{Subjective analyses using the NRS scale in groups $A$ and $B$}

All participants, regardless of treatment, showed a pre-

Table 1. Subjective analyses on the NRS scale in groups A and B

\begin{tabular}{clccccc}
\hline Group & NRS scale & Mean & Mean difference & Standard deviation & t-value & $P$-value \\
\hline Group A & Pre-treatment & 7.81 & 4.095 & 1.135 & 16.520 & 0.000 \\
& Post-treatment & 3.71 & & & 1.657 & 13.691 \\
Group B & Pre-treatment & 7.81 & 4.952 & & 0.000 \\
& Post-treatment & 2.86 & & & & \\
\hline
\end{tabular}

(NRS: numeric rating scale, Group A: patients received moist heat therapy, Group B: patients received ultrasound therapy)

Parvathi K. Balakrishnan et al: An in vivo electromyographic evaluation of pain relief using different therapies in masticatory myalgia patients. J Korean Assoc Oral Maxillofac Surg 2020

Table 2. Objective EMG analysis in groups $A$ and B (unit: $\mu \mathrm{m}$ )

\begin{tabular}{ccccccc}
\hline Group & EMG score (RMS) & Mean & Mean difference & Standard deviation & t-value & $P$-value \\
\hline Group A & Pre-treatment & 9.62 & 7.143 & 4.607 & 7.104 & 0.000 \\
& Post-treatment & 16.76 & & & 3.044 & $<0.001$ \\
Group B & Pre-treatment & 8.62 & 2.762 & 4.158 & & \\
& Post-treatment & 11.38 & & & & \\
\hline
\end{tabular}

(EMG score: electromyography score, RMS: root mean square, Group A: patients received moist heat therapy, Group B: patients received ultrasound therapy)

Parvathi K. Balakrishnan et al: An in vivo electromyographic evaluation of pain relief using different therapies in masticatory myalgia patients. J Korean Assoc Oral Maxillofac Surg 2020 
treatment mean NRS value of 7.81. However, post-treatment Group A showed an NRS mean value of 3.71 with a mean difference of 4.095 and a t-value of 16.520. Group B showed a post-treatment NRS mean value of 2.86 with a mean difference of 4.952 and a t-value of 13.691. A $P$-value of 0.000 illustrated a significant difference in NRS post-treatment readings between the two groups for the effect of pain after treatment.(Table 1)

\section{EMG scale objective analysis in groups $A$ and $B$}

Pre-treatment mean EMG values in groups A and B were $9.62 \mu \mathrm{m}$ and $8.62 \mu \mathrm{m}$, respectively. After completing treatment, Group A showed a mean EMG value of 16.76, with a mean difference of 7.143, and a t-value of 7.104; Group B showed a mean EMG value of 11.38 with a mean difference of 2.762 and a t-value of 3.044. Both groups showed a $P<0.001$, which highlighted a significant difference in EMG post-treatment, depicting improvement in muscle activity in both groups $(P<0.001)$. (Table 2$)$

\section{Subjective NRS scale comparison between the two groups}

The mean NRS differences for the two groups were compared to determine which group experienced better relief from pain. Based on the study values, Group B showed a slightly higher mean difference of 4.952 compared to Group A, which had a mean difference value of 4.095 , a t-value of 1.96 , and a significance of 0.045 . Thus, we concluded that participants who underwent ultrasound therapy responded well based on the NRS scale.(Table 3)

\section{Objective EMG comparison between two groups}

Both treatment modalities were compared on an objective scale, and moist heat was associated with a higher mean difference of $7.143 \mu \mathrm{m}$ compared to ultrasound therapy with a mean difference of $2.762 \mu \mathrm{m}$, suggesting that moist heat had a better impact on muscle improvement.(Table 4)

\section{Comparison between the two groups on subjective and objective scales}

In NRS scale, Groups A and B showed an absolute difference in mean values of 4.095 and 4.952 , respectively. This difference indicates that participants who underwent ultrasound therapy reported better symptomatic relief using the NRS scale. In EMG scale, Groups A and B showed a mean difference value of $7.143 \mu \mathrm{m}$ and $2.762 \mu \mathrm{m}$, respectively.

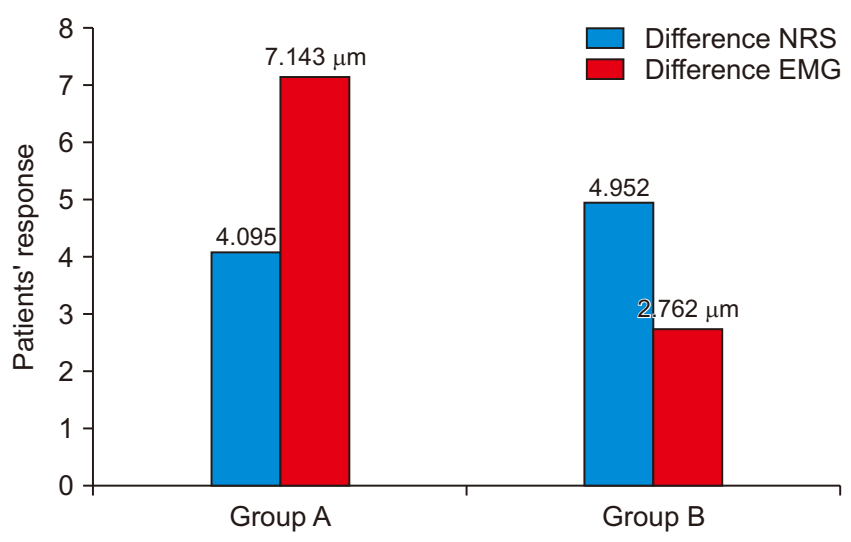

Fig. 4. Graph depicts comparison between the two groups on subjective and objective scale. (Group A: patients received moist heat therapy, Group B: patients received ultrasound therapy, NRS: numeric rating scale, EMG: electromyography)

Parvathi K. Balakrishnan et al: An in vivo electromyographic evaluation of pain relief using different therapies in masticatory myalgia patients. J Korean Assoc Oral Maxillofac Surg 2020

Table 3. Subjective NRS scale comparison between the two groups

\begin{tabular}{cccccc}
\hline Group & Number & Mean difference & Standard deviation & t-value & $P$-value \\
\hline Group A & 21 & 4.095 & 1.135 & 1.96 & 0.045 \\
Group B & 21 & 4.952 & 1.657 & & \\
\hline
\end{tabular}

(NRS: numeric rating scale, Group A: patients received moist heat therapy, Group B: patients received ultrasound therapy)

Parvathi K. Balakrishnan et al: An in vivo electromyographic evaluation of pain relief using different therapies in masticatory myalgia patients. J Korean Assoc Oral Maxillofac Surg 2020

Table 4. Objective EMG comparison between the two groups (unit: $\mu \mathrm{m}$ )

\begin{tabular}{cccccc}
\hline Group & Number & Mean difference & Standard deviation & t-value & $P$-value \\
\hline Group A & 21 & 7.143 & 4.607 & 3.235 & 0.002 \\
Group B & 21 & 2.762 & 4.158 & & \\
\hline
\end{tabular}

(EMG scale: electromyography scale, Group A: patients received moist heat therapy, Group B: patients received ultrasound therapy)

Parvathi K. Balakrishnan et al: An in vivo electromyographic evaluation of pain relief using different therapies in masticatory myalgia patients. J Korean Assoc Oral Maxillofac Surg 2020 
Although both groups showed improvement in masticatory muscle activity, the subjects in Group A exhibited a relatively higher recovery on objective analysis with EMG.(Fig. 4)

\section{Discussion}

Currently, there are no reliable procedures or devices that can be used by researchers or practitioners to diagnose or evaluate the presence and severity of $\mathrm{TMD}^{6}$. In the majority of patients with TMD, the muscles are either hyperactive or hypoactive; this abnormal activity can be utilized as an efficient method to detect any functionally disturbed mandibular conditions. In this analysis, EMG was used to test this asymmetry in muscle activity ${ }^{17}$. Since 1950, EMG has being used in dentistry to evaluate muscle activity due to its ability to assess the electrical characteristics and behavior of impacted muscles.

In a systematic review by Suvinen and Kemppainen ${ }^{18}$, EMG was suggested as an adjunct research tool to study masticatory functions. In 1991, Cooper et al. ${ }^{19}$ discovered that EMG of certain masticatory muscles in patients with clinically diagnosed craniomandibular dysfunction is a clinically helpful strategy for quantifying musculoskeletal dysfunction. Wang and peers noted an increase in SEMG activity in masticatory muscles due to pain that emanated from inner derangements. Santana-Mora et al. ${ }^{20}$ found lower EMG values in chronic TMD patients, while Gervais et al. ${ }^{21}$ found higher resting EMG values in TMD patients.

From the subjective analysis, it is evident that the participants in both treatment modality groups had a significant response on the NRS scale, and the majority of patients showed considerable relief from the pain after therapy. Although the pain level on the NRS shifted to mild from severe for all patients, the statistical analysis of the collected data given in Table 3 shows that the mean differences in NRS scores for the treatment modalities were 4.095 and 4.952, respectively. These results statistically indicate ultrasound as a better method to alleviate pain, as the patients marked a higher difference on the NRS scale than that of the moist heat group. This observation is supported by a study performed by Esposito et al. ${ }^{22}$ in 1984, which stated that ultrasonic therapy is extremely efficient in alleviating myofascial pain. In 1999, van der Windt et al. ${ }^{23}$ evaluated the effectiveness of ultrasound therapy for treating musculoskeletal disorders, and the review supported use of ultrasonic therapy in musculoskeletal disorder treatment.

On objective analysis, the increase in mean value of EMG amplitude after therapy suggested a higher amplitude registration in the EMG, which indicates enhanced muscle activity. Hence, as in Table 4, moist heat therapy showed a mean difference of $7.143 \mu \mathrm{m}$, which is significantly higher than the value for ultrasound therapy, which was $2.762 \mu \mathrm{m}$. This higher mean difference suggests that patients who underwent moist heat therapy had better muscle activity after the treatment, which suggests that moist heat therapy is superior to ultrasound for restoring the muscle activity of the affected muscle.

Based on these results, subjective assessment (NRS scale) indicates that ultrasound is superior to moist heat, while objective analysis (EMG scale) indicates that moist heat therapy is preferable to ultrasound. Since the study focused on the two parameters of pain and muscle activity, the NRS reading depends on patient senses; therefore, the mean difference comparison alone is not sufficient to determine the best treatment modality.

For a treatment to be qualified as the best treatment modality, it should be effective and equally consistent in all aspects. The standard deviation should be compared to assess the consistency for ultrasound and moist heat approaches. Table 3 shows that the treatments are equally consistent because the standard deviation values are similar. The results for enhanced muscle activity showed that moist heat was very consistent, and that the standard deviation was just above one (1.005). However, after one week of observation, the ultrasound approach was found to lack consistency for improving muscle function as it was associated with a higher standard deviation of 4.158 .

This finding is in agreement with a previous finding by Funk et al. ${ }^{24}$ in 2001, showing that moist heat implementation for 20 minutes offered better hamstring flexibility than static stretching, which indicated enhancement for muscle fitness and connective tissue with moist heat therapy. This is due to enhanced vasodilation and an analgesic impact that increases the pain threshold, relieves muscle spasms by decreasing muscle spindle activity, and increases the extensibility of collagen fibres. For every $10^{\circ} \mathrm{C}$ increase in temperature, cellular and metabolic activity in the cells increases by two- to threefold.

Similarly, Petrofsky et al. ${ }^{25}$ concluded in his study that moist heat therapy had enhanced benefits compared to dry heat therapy in a shorter time. Further research from Petrofsky et al. ${ }^{26}$ revealed that the result was attributable either to increased heat flux through the skin via moist air or to changes in the ionic environment around skin thermo receptors. 
Gam and Johannsen ${ }^{27}$ published a systematic review on 22 randomized clinical trials that assessed the effectiveness of ultrasound therapy for musculoskeletal conditions. They concluded that there was little evidence of the effectiveness of ultrasound therapy from well-designed trials, yet they hypothesized that ultrasound therapy might augment the effect of exercise therapy. Therefore, the effect of ultrasound therapy in improving muscle strength was augmented when it was performed along with home exercise regimens.

In addition, Fouda ${ }^{28}$ in 2014 and Young and Dyson ${ }^{29}$ in 1990 , promoted the use of ultrasound therapy in combination with hyperthermia. It was thought that the combined effect of two or more treatment approaches would provide a synergistic effect that imparts a better therapy. Another study by El-Batouty et al. ${ }^{30}$ in 1986 found that ultrasound had a significant impact on tissue regeneration, which was evident starting in the fifth week. Hence, these results suggest the need for further research to document the effectiveness of ultrasound therapy on relieving the signs of TMD by employing studies with longer treatment times, along with incorporation of mouth stretching exercises.

Temporomandibular disorders can be treated with moist heat therapy as a reliable and self-manageable treatment modality. EMG can be utilized as a diagnostic tool to analyze the effectiveness of treatments in relieving muscle hyperactivity.

\section{Conclusion}

After thorough evaluation of clinical and statistical data, the study concluded that, although both therapies significantly reduced the symptomatic response (pain), moist heat improved muscle activity both statistically and clinically compared to ultrasound over a shorter treatment duration.

\section{ORCID}

Parvathi K. Balakrishnan, https://orcid.org/0000-00018588-4439

Sowmya M. Kumar, https://orcid.org/0000-0003-0696-0697

Purushotham Chippala, https://orcid.org/0000-0002-7319-8375

Chethan Hegde, https://orcid.org/0000-0002-3751-7789

\section{Authors' Contributions}

P.K.B. participated in data collection and wrote the manuscript. S.M.K. participated in study design and helped to draft the manuscript. P.C. participated in study design, coordinated to perform the study and performed the statistical analysis. C.H. has participated in study design, performed statistical analysis and reviewed the manuscript. All authors reviewed and approved the final manuscript.

\section{Ethics Approval and Consent to Participate}

The study was approved by the Ethical Committee of $\mathrm{AB}$ Shetty Memorial Institute of Dental Sciences (No. ABSM/ EC31/2017). Informed consent from patients between 20-50 years of age was obtained.

\section{Consent for Publishing Photographs}

Written informed consent was obtained from the patients for publication of this article and accompanying images.

\section{Conflict of Interest}

No potential conflict of interest relevant to this article was reported.

\section{References}

1. Okeson JP. Management of temporomandibular disorders and occlusion. 7th ed. St. Louis: Elsevier; 2013.

2. Chethan H, Ganaraj S, Krishna Prasad D. To evaluate the effect of moist heat fomentation therapy in relieving symptoms of pain related temporomandibular muscle pain disorder. Int J Curr Res 2015;7:17393-6.

3. McNeill C. Management of temporomandibular disorders: concepts and controversies. J Prosthet Dent 1997;77:510-22. https:// doi.org/10.1016/s0022-3913(97)70145-8

4. Mohl ND, Lund JP, Widmer CG, McCall WD Jr. Devices for the diagnosis and treatment of temporomandibular disorders. Part II: electromyography and sonography. J Prosthet Dent 1990;63:332-6. https://doi.org/10.1016/0022-3913(90)90207-s

5. Klasser GD, Okeson JP. The clinical usefulness of surface electromyography in the diagnosis and treatment of temporomandibular disorders. J Am Dent Assoc 2006;137:763-71. https://doi. org/10.14219/jada.archive.2006.0288

6. Carrara SV, Conti PCR, Barbosa JS. Statement of the $1^{\text {st }}$ consensus on temporomandibular disorders and orofacial pain. Dent Press J Orthod 2010;15:114-20.

7. Gray RJM, Quayle AA, Hall CA, Schofield MA. Temporomandibular pain dysfunction: can electrotherapy help? Physiotherapy 1995;81:47-51. https://doi.org/10.1016/S0031-9406(05)67036-8

8. Abouelhuda AM, Khalifa AK, Kim YK, Hegazy SA. Non-invasive different modalities of treatment for temporomandibular disorders: review of literature. J Korean Assoc Oral Maxillofac Surg 2018;44:43-51. https://doi.org/10.5125/jkaoms.2018.44.2.43

9. Miller DL, Smith NB, Bailey MR, Czarnota GJ, Hynynen K, Makin IR; Bioeffects Committee of the American Institute of Ultrasound in Medicine. Overview of therapeutic ultrasound applications and safety considerations. J Ultrasound Med 2012;31:623-34. https://doi.org/10.7863/jum.2012.31.4.623 
10. Schiffman E, Ohrbach R, Truelove E, Look J, Anderson G, Goulet JP, et al.; International RDC/TMD Consortium Network, International association for Dental Research; Orofacial Pain Special Interest Group, International Association for the Study of Pain. Diagnostic criteria for temporomandibular disorders (DC/TMD) for clinical and research applications: recommendations of the International RDC/TMD Consortium Network* and Orofacial Pain Special Interest Group†. J Oral Facial Pain Headache 2014;28:627. https://doi.org/10.11607/jop.1151

11. Breivik H, Borchgrevink PC, Allen SM, Rosseland LA, Romundstad L, Hals EK, et al. Assessment of pain. Br J Anaesth 2008;101:17-24. https://doi.org/10.1093/bja/aen103

12. Poindexter RH, Wright EF, Murchison DF. Comparison of moist and dry heat penetration through orofacial tissues. Cranio 2002;20:28-33. https://doi.org/10.1080/08869634.2002.11746187

13. Erickson RI. Ultrasound--a useful adjunct in temporomandibular joint therapy. Oral Surg Oral Med Oral Pathol 1964;18:176-9. https://doi.org/10.1016/0030-4220(64)90422-0

14. Möller E, Sheikholeslam A, Lous I. Response of elevator activity during mastication to treatment of functional disorders. Scand J Dent Res 1984;92:64-83. https://doi.org/10.1111/j.1600-0722.1984. tb00861.x

15. Sheikholeslam A, Möller E, Lous I. Postural and maximal activity in elevators of mandible before and after treatment of functional disorders. Scand J Dent Res 1982;90:37-46. https://doi.org/10.1111/ j.1600-0722.1982.tb01522.x

16. Yemm R. A neurophysiological approach to the pathology and aetiology of temporomandibular dysfunction. J Oral Rehabil 1985;12:343-53. https://doi.org/10.1111/j.1365-2842.1985. tb01289.x

17. Ries LG, Alves MC, Bérzin F. Asymmetric activation of temporalis, masseter, and sternocleidomastoid muscles in temporomandibular disorder patients. Cranio 2008;26:59-64. https://doi. org $/ 10.1179 / \mathrm{crn} .2008 .008$

18. Suvinen TI, Kemppainen P. Review of clinical EMG studies related to muscle and occlusal factors in healthy and TMD subjects. J Oral Rehabil 2007;34:631-44. https://doi.org/10.1111/j.13652842.2007.01769.x

19. Cooper BC, Cooper DL, Lucente FE. Electromyography of masticatory muscles in craniomandibular disorders. Laryngoscope 1991;101:150-7. https://doi.org/10.1288/00005537-19910200000009

20. Santana-Mora U, Cudeiro J, Mora-Bermúdez MJ, Rilo-Pousa B, Ferreira-Pinho JC, Otero-Cepeda JL, et al. Changes in EMG activity during clenching in chronic pain patients with unilateral temporomandibular disorders. J Electromyogr Kinesiol 2009;19:e543-
9. https://doi.org/10.1016/j.jelekin.2008.10.002

21. Gervais RO, Fitzsimmons GW, Thomas NR. Masseter and temporalis electromyographic activity in asymptomatic, subclinical, and temporomandibular joint dysfunction patients. Cranio 1989;7:52-7. https://doi.org/10.1080/08869634.1989.11678268

22. Esposito CJ, Veal SJ, Farman AG. Alleviation of myofascial pain with ultrasonic therapy. J Prosthet Dent 1984;51:106-8. https://doi. org/10.1016/s0022-3913(84)80115-8

23. van der Windt DA, van der Heijden GJ, van den Berg SG, ter Riet G, de Winter AF, Bouter LM. Ultrasound therapy for musculoskeletal disorders: a systematic review. Pain 1999;81:257-71. https://doi. org/10.1016/s0304-3959(99)00016-0

24. Funk D, Swank AM, Adams KJ, Treolo D. Efficacy of moist heat pack application over static stretching on hamstring flexibility. J Strength Cond Res 2001;15:123-6.

25. Petrofsky J, Bains G, Prowse M, Gunda S, Berk L, Raju C, et al. Dry heat, moist heat and body fat: are heating modalities really effective in people who are overweight? J Med Eng Technol 2009;33:361-9. https://doi.org/10.1080/03091900802355508

26. Petrofsky J, Bains G, Prowse M, Gunda S, Berk L, Raju C, et al. Does skin moisture influence the blood flow response to local heat? A re-evaluation of the Pennes model. J Med Eng Technol 2009;33:532-7. https://doi.org/10.1080/03091900902952683

27. Gam AN, Johannsen F. Ultrasound therapy in musculoskeletal disorders: a meta-analysis. Pain 1995;63:85-91. https://doi. org/10.1016/0304-3959(95)00018-n

28. Fouda AAEH. Ultrasonic therapy as an adjunct treatment of temporomandibular joint dysfunction. J Oral Maxillofac Surg 2014;117:232-37.

29. Young SR, Dyson M. Effect of therapeutic ultrasound on the healing of full-thickness excised skin lesions. Ultrasonics 1990;28:17580. https://doi.org/10.1016/0041-624x(90)90082-y

30. El-Batouty MF, el-Gindy M, el-Shawaf I, Bassioni N, el-Ghaweet A, el-Emam A. Comparative evaluation of the effects of ultrasonic and ultraviolet irradiation on tissue regeneration. Scand J Rheumatol 1986;15:381-6. https://doi.org/10.3109/03009748609098208

How to cite this article: Balakrishnan PK, Kumar SM, Chippala P, Hegde C. An in vivo electromyographic evaluation of pain relief using different therapies in masticatory myalgia patients. J Korean Assoc Oral Maxillofac Surg 2020;46:321-327. https://doi. org/10.5125/jkaoms.2020.46.5.321 